Revista Brasileira de Agricultura Irrigada v.9, nº.5, p. 335 - 343, 2015

ISSN 1982-7679 (On-line)

Fortaleza, CE, INOVAGRI - http://www.inovagri.org.br

DOI: $10.7127 /$ rbai.v9n500331

Protocolo 331.15 - 10/06/2015 Aprovado em 01/09/2015

\title{
EVAPOTRANSPIRAÇÃO E COEFICIENTE DE CULTIVO DA HELICÔNIA GOLDEN TORCH NO VALE DO SÃO FRANCISCO
}

Thomaz da Silva Felisberto ${ }^{1}$, Damiana de Oliveira Silva ${ }^{2}$, João Rodrigues de Souza Filho ${ }^{3}$, Wilian José dos Santos ${ }^{4}$, Magnus Dall'igna Deon ${ }^{5}$, Lígia Borges Marinho ${ }^{6}$.

\begin{abstract}
RESUMO
A floricultura brasileira vem se consolidando como uma atividade lucrativa, no entanto a falta de informações vem se tornando um fator limitante a produção. O estudo foi conduzido em ambiente semiprotegido no Vale do São Francisco, Juazeiro - BA, com a cultura de Helicônia Gonden Torch, de 30 de novembro de 2013 a 21 de fevereiro de 2014. O objetivo do trabalho foi determinar a evapotranspiração da cultura e o coeficiente de cultivo da Helicônia Golden Torch no Vale do São Francisco. As plantas foram cultivadas em solo textura franco-arenosa, em canteiros, com espaçamento de 0,5 $\mathrm{m} \times 2,0 \mathrm{~m}$, irrigadas por gotejamento, diariamente. A evapotranspiração da cultura foi quantificada por balanço hídrico do solo. Utilizando-se tensiômetros para determinação da umidade atual do solo, determinou-se a drenagem e a variação de armazenamento de água no solo. A helicônia Golden Torch apresentou uma taxa de evapotranspiração média de $2,78 \mathrm{~mm} \mathrm{~d}^{-1}$, totalizando $231,2 \mathrm{~mm}$ no período estudado. Os valores médios dos coeficientes de cultivos encontrados foram de 0,63 na fase inicial, 0,80 na fase vegetativa e de 1,01 na fase de florescimento-colheita.
\end{abstract}

Palavras-chave: evapotranspiração da cultura, Helicônia ssp, balanço hídrico.

\section{EVAPOTRANSPIRATION AND RATE HELICONIA GOLDEN TORCH FARMING IN SÃO FRANCISCO VALLEY}

\footnotetext{
ABSTRACT

The Brazilian floriculture has been consolidated as a profitable activity, however the lack of information is becoming a limiting factor to production. The study was conducted in semi-protected environment in the São Francisco Valley, Juazeiro - BA, with the culture of Heliconia Gonden Torch, of 30 November 2013 to 21 February 2014. The objective was to determine the crop evapotranspiration and the crop coefficient of Heliconia Golden Torch in the São Francisco Valley. The plants were grown in soil sandy

${ }^{1}$ Discente de Engenharia agronômica, UNEB, Campus III - Juazeiro-BA, Brasil, Email: thomazvilbe@hotmail.com

${ }^{2}$ Discente, Mestrado Horticultura Irrigada, UNEB, Campus III, Juazeiro-BA, Brasil, Email: damy_sylva@hotmail.com

${ }^{3}$ Discente de Engenharia Agronômica, Uneb/Dept ${ }^{0}$ Tecnologia e Ciências Sociais - Juazeiro-BA, Brasil, Email: joaorfilho00@gmail.com

4 Discente de Engenharia Agronômica, Uneb/Dept ${ }^{\mathrm{O}}$ Tecnologia e Ciências Sociais - Juazeiro-BA, Brasil, Email: wjsantos18@gmail.com

${ }^{5}$ Doutor, Pesquisador Embrapa Semiárido, Petrolina, PE, Brasil, Email: magnus.deon@embrapa.br

${ }^{6}$ Prof., Doutor, Uneb/Dept ${ }^{0}$ Tecnologia e Ciências Sociais, Juazeiro-BA, Brasil, Email: ligia.bmarinho@gmail.com
} 
loam texture, in beds, with spacing of $0.5 \mathrm{mx} 2.0 \mathrm{~m}$, drip irrigated daily. The crop evapotranspiration was quantified by soil water balance. Using a tensiometer to determine the soil moisture present, we determined the water drainage and storage of variation in soil. The heliconia Golden Torch averaged evapotranspiration rate of $2.78 \mathrm{~mm} \mathrm{~d}^{-1}$, totaling $231.2 \mathrm{~mm}$ during the study period. The mean values of crop coefficients found were 0.63 at the initial stage, 0.80 in the vegetative phase and 1.01 in the flowering-harvest phase.

Keywords: crop evapotranspiration, Heliconia spp, water balance.

\section{INTRODUÇÃO}

No Submédio do Vale do São Francisco a floricultura pode ser considerada como boa alternativa de diversificação de cultivo, pois, em pequenas áreas pode ocasionar boa rentabilidade por unidade de área cultivada, com maior rapidez de retorno e gerar empregos diretos e indiretos. Dentre as flores tropicais destaca-se a cultivar Golden Torch (Heliconia psittacorum x H. spathocircinata) a qual apresenta boa aceitabilidade no mercado consumidor (MOSCA et al., 2005; JUNQUEIRA e PEETZ, 2007).

A quantificação da necessidade hídrica das culturas pode ser determinada com base nos dados de solo e planta. O método do balanço hídrico para a quantificação da evapotranspiração de diferentes culturas tem sido adotado com sucesso, sendo utilizada a equação de Reichardt (1985), e para a quantificação da drenagem e/ou ascensão capilar a equação Buckingham - Darcy, escrita de forma simplificada por REICHARDT (1985).

No nordeste brasileiro foi verificada a presença de pesquisas científicas que tiveram como tema a estimativa da demanda hídrica e dos coeficientes de cultura das flores tropicais, pelo método de balanço hídrico, apenas em regiões litorâneas (GOMES et al., 2006; 2008; GONDIM et al., 2008).

Em estudo realizado por Gomes et al. (2006) em ambiente protegido, na Região Litorânea do Estado do Ceará pode-se determinar a evapotranspiração e o coeficiente de cultivo da helicônia variedade Alan Carle, pelo método do balanço hídrico e o Kc mediante da evapotranspiração de referência (ETo), estimada com o tanque classe A, posicionado no interior e exterior do ambiente protegido, para a fase inicial, vegetativa e floração, sendo verificadas diferenças nos valores de ETc e kc de acordo com a modificação climática do local (ambiente protegido e campo externo).

Ao pesquisar a cultura da Alpinia purpura, em ambiente protegido em Paraipaba, CE, foi observado um valor médio de evapotranspiração de 2,4 $\mathrm{mm} \mathrm{d}^{-1}$ e de coeficientes de cultivo (Kc), obtidos pela evapotranspiração de referência estimada pelo tanque Classe $\mathrm{A}$, foram de 0,72 ; 1,07 e 0,77 respectivamente para a fase vegetativa, floração e colheita (Gomes et al., 2008).

GONDIM et al. (2008) estimaram a demanda hídrica e o coeficiente de cultivo da Heliconia Bihai em Paraipaba-CE, utilizando o método de balanço hídrico do solo para encontrar a ETc e os métodos do Tanque Classe A e Penman-Monteith para estimar a ETo, estes autores reportaram diferenças dos coeficientes em função do método utilizado na estimativa da ETo. Todavia, são escassas as informações a respeito da demanda hídricas desta cultura, para o planejamento e implantação no semiárido nordestino do Brasil.

A estimativa da evapotranpiração de flores tropicais no Submédio do Vale do São Francisco tem se baseado, na maioria das vezes, em dados extrapolados de outras regiões ou de outras culturas, até mesmo de estudo com bananeira (Bassoi et al., 2001); acarretando erros no manejo da irrigação da cultura da helicônia para essa região.

No Submédio do Vale do São Francisco os dados meteorológicos são disponibilizados no site da Embrapa Semiárido e podem ser utilizados junto aos coeficientes de cultivo para estimativa da evapotranspiração da cultura, para manejo da irrigação. Por este motivo, é fundamental o ajuste dos coeficientes de cultivo para a condição de solo e cultura na região em que será empregado. 
Dessa forma, o objetivo do estudo foi determinar a demanda hídrica e o coeficiente de cultivo da flor tropical, helicônia Golden Torch, em ambiente protegido, em Juazeiro, BA.

\section{METODOLOGIA}

O estudo foi realizado em ambiente semiprotegido no campo experimental da Universidade do Estado da Bahia, no Vale do São Francisco, município de Juazeiro - BA $\left(9^{\circ}\right.$ 24’ S; 40 30’ W; 368 m de altitude. O clima da região é classificado como semiárido com pluviosidade média anual de 400 a $600 \mathrm{~mm}$.

Foi cultivada a helicônia Golden Torch, por propagação de rizoma, em solo textura franco-arenosa, em canteiros, com espaçamento de $0,5 \mathrm{~m} \times 2,0 \mathrm{~m}$.

A caracterização físico-hídrica do solo foi realizada na Embrapa Semiárido conforme Embrapa, (1997), para isso, foram coletadas amostras deformadas nas camadas do solo de 020 e 20-40 cm (Tabela 1).

Tabela 1. Resultados análise físico-hídrica dos solos utilizados no experimento.

\begin{tabular}{|c|c|c|c|c|c|c|}
\hline \multirow{2}{*}{$\begin{array}{l}\text { Análises } \\
\text { Físicas do } \\
\text { solo }\end{array}$} & Localidade & $\begin{array}{l}\text { Areia } \\
\text { (g/kg) }\end{array}$ & $\begin{array}{l}\text { Argila } \\
\text { (g/kg) }\end{array}$ & Silte (g/kg) & $\begin{array}{l}\text { Classificação } \\
\text { textural }\end{array}$ & d.s (kg dm-3) \\
\hline & UNEB- & 726,80 & 213,0 & 60,20 & Franco Arenoso & 1,40 \\
\hline $\begin{array}{c}\text { Curva } \\
\text { retenção }\end{array}$ & 0,006 & 0,010 & 0,030 & $\begin{array}{r}\text { - Мpa } \\
\text { 0,060 }\end{array}$ & 0,100 & 1,50 \\
\hline $\begin{array}{l}\text { de agua } \\
\text { no solo }\end{array}$ & 16,63 & 12,29 & 9,69 & 8,34 & 7,52 & 5,53 \\
\hline
\end{tabular}

A irrigação foi realizada, diariamente, por gotejamento, com emissores in-line espaçados em $0,5 \mathrm{~m}$ e com vazão de $2 \mathrm{~L} \mathrm{~h}^{-1}$. Foram instaladas cinco baterias de tensiômetro a $10 \mathrm{~cm}$, $30 \mathrm{~cm}$ e $50 \mathrm{~cm}$ da superfície do solo, representando as camadas de $0-20 \mathrm{~cm}, 20-40$ e 40-60 cm, com o objetivo de determinar o potencial mátrico, umidade do solo, a lâmina de irrigação, drenagem profunda e ascensão capilar.

Os valores de potenciais mátricos foram convertidos em umidade gravimétrica mediante curva de retenção de água no solo, a qual foi determinada submetendo-se amostras de solo aos potenciais mátricos de: $-0,006$; $-0,01 ;-0,03$; 0,06; -0,10; -1,5MPa utilizando o método da Centrífuga conforme EMBRAPA(1997) e obtendo-se os valores de umidade gravimétrica correspondentes. Os dados de umidade em função dos valores de potenciais mátricos foram ajustados a equação de regressão.

A lâmina aplicada em cada irrigação foi determinada com base nos potenciais mátricos utilizando-se as médias das leituras dos tensiômetros instalados a 10 e a $30 \mathrm{~cm}$, representado a camada de $0-20 \mathrm{~cm}$ e de $20-40$ $\mathrm{cm}$.

A Evapotranspiração de referência (ETo) foi estimada pelo método do tanque classe "A" localizado fora do telado, em uma área gramada com 10 metros de bordadura, com Kp calculado mediante dados de uma estação meteorológica automática localizada a $100 \mathrm{~m}$ do telado.

O coeficiente de cultivo (Kc) para as diferentes fases fenológicas da helicônia, foi obtido por meio da expressão proposta por Doorenbos \& Kassam (1994).

A evapotranspiração da cultura (ETc) foi obtida através do método de balanço hídrico calculada para a camada de $0-40 \mathrm{~cm}$ pela equação simplifica do balanço hídrico:

$$
\mathrm{ETc}=\mathrm{P}+\mathrm{I} \pm \mathrm{Qz}-\Delta \mathrm{A}
$$

em que:

ETc - evapotranspiração da cultura (mm); P - precipitação pluvial (mm); 
I - irrigação (mm);

Qz - drenagem profunda ou ascensão capilar (mm);

$\Delta \mathrm{A}$ - variação do armazenamento da água do solo, para o intervalo de tempo considerado no balanço.

A variação de armazenamento da água no solo foi obtida mediante a equação de Reichardt (1985). A drenagem e ascensão capilar foram estimadas para a profundidade abaixo da zona efetiva das raízes pela equação de Buckingham Darcy, modificada por Reichardt (1985). Para a determinação da condutividade hidráulica do solo saturado (Ko) foram coletadas amostras de solo deformadas, na camada de $0-40 \mathrm{~cm}$, pelo método do permeâmetro de carga constante.

As lâminas de irrigação foram calculadas diariamente através de tensiômetros mantendo sempre a umidade do solo próximo a representada pela a capacidade de campo.

A irrigação foi realizada por gotejamento, com emissores espaçados de $0,5 \mathrm{~m}$, vazão de $2 \mathrm{~L}$ $\mathrm{h}^{-1}$, pressão de operação de $100 \mathrm{kPa}$, frequência diária, mantendo o solo com umidade próxima à umidade na capacidade de campo.

A variação de armazenamento da água no solo foi obtida mediante a equação de Reichardt (1985).

$$
\Delta \mathrm{A}=\left(\bar{\theta}_{2}-\bar{\theta}_{1}\right) \mathrm{Z}
$$

Em que,

$\Delta \mathrm{A}$ - variação do armazenamento da água do solo;

$\bar{\theta}_{2}$ - umidade média até a profundidade de 0,40 m no dia da irrigação $\left(\mathrm{cm}^{3} \mathrm{~cm}^{-3}\right)$;

$\bar{\theta}_{1}$ - umidade média até a profundidade de 0,40 $\mathrm{m}$ no dia da irrigação anterior $\left(\mathrm{cm}^{3} \mathrm{~cm}^{-3}\right)$;

$\mathrm{Z}$ - profundidade adotada para o balanço $(0,40 \mathrm{~m})$.

O balanço hídrico foi iniciado 40 dias após o transplantio e foi até décima sexta colheita.
As fases fenológicas foram determinadas, anotando-se a duração de cada uma delas pela observação da altura e área foliar. Quantificou-se também o número de perfilho e número de inflorescências por planta. A altura da planta foi aferida com auxilio de trena, a partir do solo até o ápice da planta, foram realizadas aferições de comprimento e largura das folhas com auxilio de régua.

A área foliar foi estimada multiplicação do produto do comprimento e largura (CXL) a um fator correlação (f), o qual foi obtido por regressão linear da área do retângulo (CXL) e da área foliar determinada em 20 folhas por integrador de área foliar (Model 3100 Area Meter LI- COR).

O número de perfilho foi computado levando em consideração aqueles que possuíam pelo menos uma folha formada.

A partir dos 110 DAT foram colhidas as hastes de flores e quantificado a produção, a colheita, foi realizada seguindo as recomendações regionais e em horários mais amenos, totalizando 16 colheitas. Sendo realizada através de um corte na base da haste floral, ao nível do solo, com auxílio de uma tesoura de poda.

Os valores de altura de planta, área foliar, altura da haste e número de flores por colheita foram expresso em função dos dias após transplantio e ajustados por regressão.

\section{RESULTADOS E DISCUSSÃO}

As lâminas de irrigação aplicadas no experimento e as precipitações ocorridas entre os 40 e 123 dias após transplantio podem ser visualizados na Figura 1. Os dados de irrigação referente à fase inicial, não foram apresentados, pois, a mesma foi atingida antes do início da quantificação do balanço hídrico, o qual teve início aos 40 DAT. 


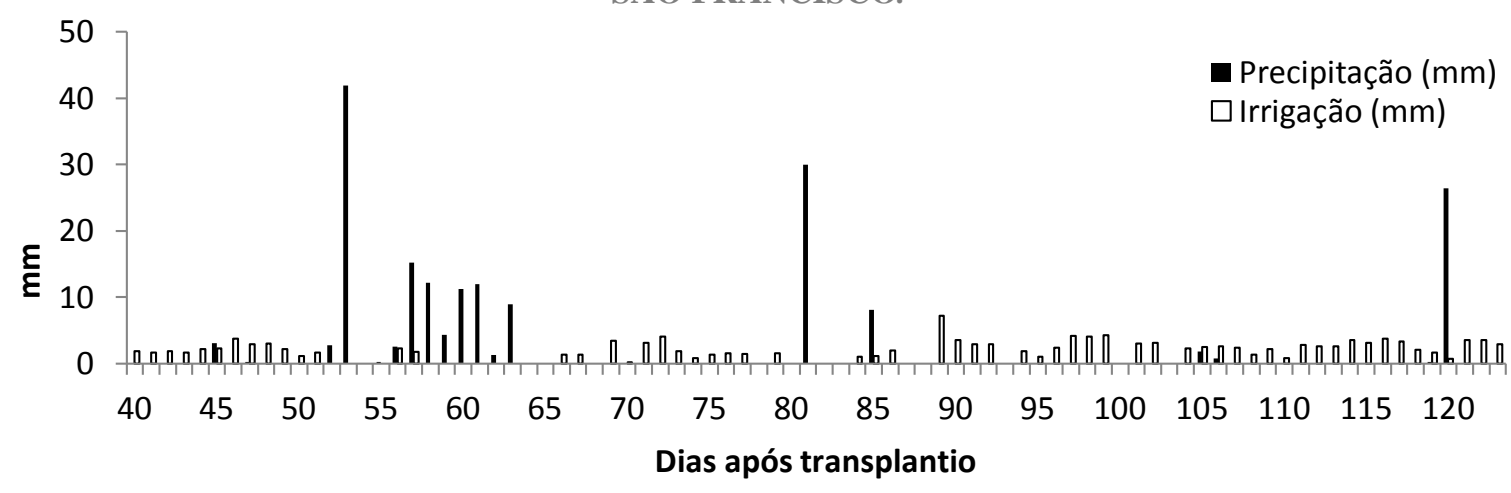

Figura 1. Precipitação e irrigação (lâmina bruta) ao longo do ciclo da Helicônia Golden Torch, dos 40 aos 122 dias após transplantio, em ambiente semi-protegido, Juazeiro-BA.

A precipitação efetiva total ocorrida durante o experimento foi de 183,1 mm, distribuída de forma irregular. Verificou-se que as precipitações contribuíram significativamente com a umidade do solo além da capacidade de campo, provocando uma redução na necessidade de irrigação.

As lâminas de água, aplicadas através da irrigação, variaram de $0,23 \mathrm{~mm}$ a $6 \mathrm{~mm}$, totalizando 146,99 mm, para um ciclo de 123 dias após transplantio (DAT).

Resultados semelhantes de lâminas acumuladas aplicadas (130,2 mm), num ciclo fenológico de 189 DAT, foram relatadas por Gomes et al. (2008) em estudo sobre a evapotranspiração e coeficiente de cultivo da Alpinia purpurata em Paraipaba, CE, contudo, no período do estudo do referido autor, houve uma superior contribuição da precipitação (390,9 $\mathrm{mm})$.

Em pesquisa realizada por Gondim et al. (2008) com Helicônia bihai L. em ambiente protegido, telado com $50 \%$ de sombreamento, em Paraipaba - CE, foi reportado um valor de 174,7 mm de água perdida por evapotranspiração da cultura, a qual foi determinada balanço hídrico do solo, a partir dos 60 dias após transplantio das mudas até o início da colheita das hastes (185 DAT), no entanto, há uma maior contribuição de precipitações totais (926,9 mm).

Nota-se que as precipitações, nos trabalhos de pesquisa citados, assim como nesta pesquisa, contribuíram significativamente para o aumento da umidade do solo, por se tratar de ambiente telado, ocasionaram uma redução na necessidade de irrigação, o mesmo foi verificado neste estudo.

Os resultados referentes aos potenciais matriciais obtidos nas camadas de $0-20 \mathrm{~cm}$ e20$40 \mathrm{~cm}$ do solo, dos 40 aos 123 DAT da heliconia Golden Torch encontram-se na Figura 2.

\section{Dias após transplantio (DAT)}

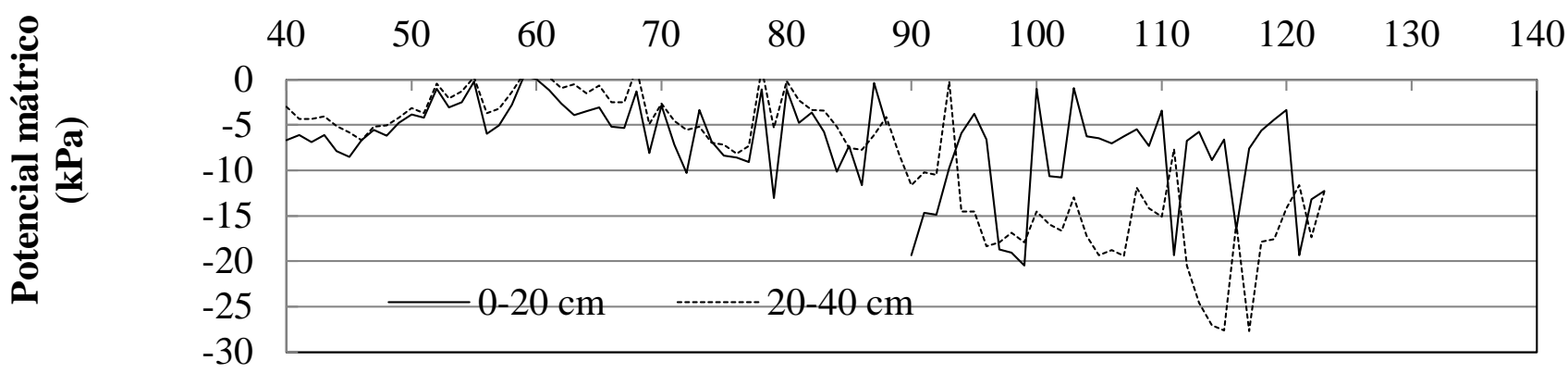

Figura 2. Potencial matricial do solo, camadas de $0-20 \mathrm{~cm}$ e $20-40 \mathrm{~cm}$, dos 40 aos 122 DAT 
Observa-se que o potencial mátrico ficou cada vez mais negativo, em ambas às profundidades do solo em função do crescimento da planta (Figura 4), aumento de área foliar (figura 3) e a partir da fase de floração, consequentemente, devido ao aumento da necessidade hídrica das plantas. A partir dos 90 DAT se verificou um aumento da contribuição da camada de 20-40 cm, devido maior desenvolvimento radicular, aumento da área foliar (Figura 3), altura da planta (Figura 4) e número de flores (Figura 5).

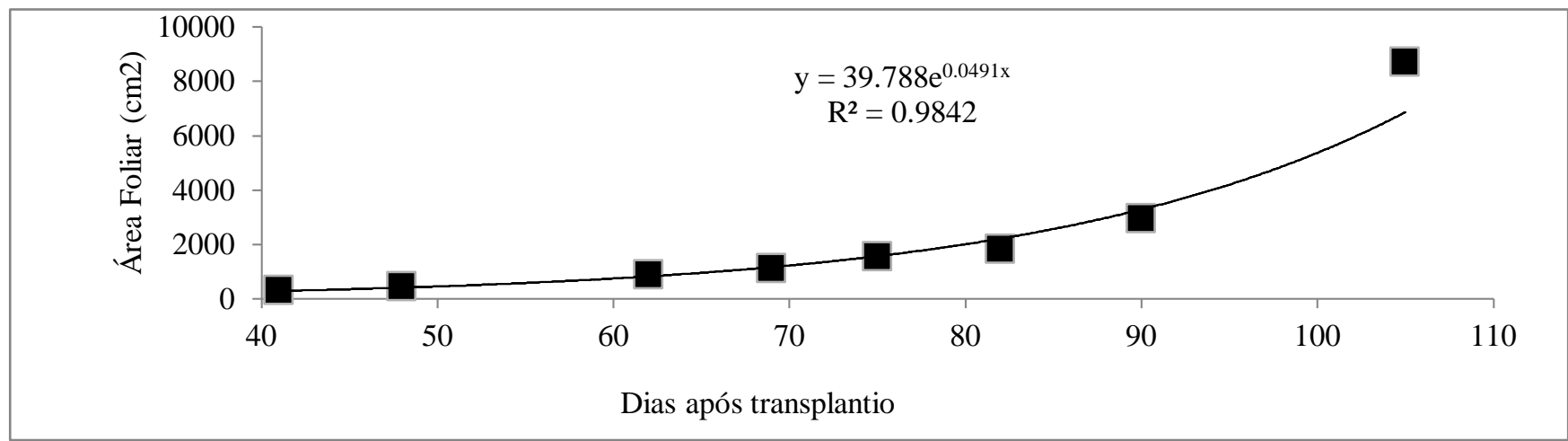

Figura 3. Área foliar dos 40 aos 110 DAT, heliconia Golden Torch, em ambiente semiprotegido, Juazeiro-BA.

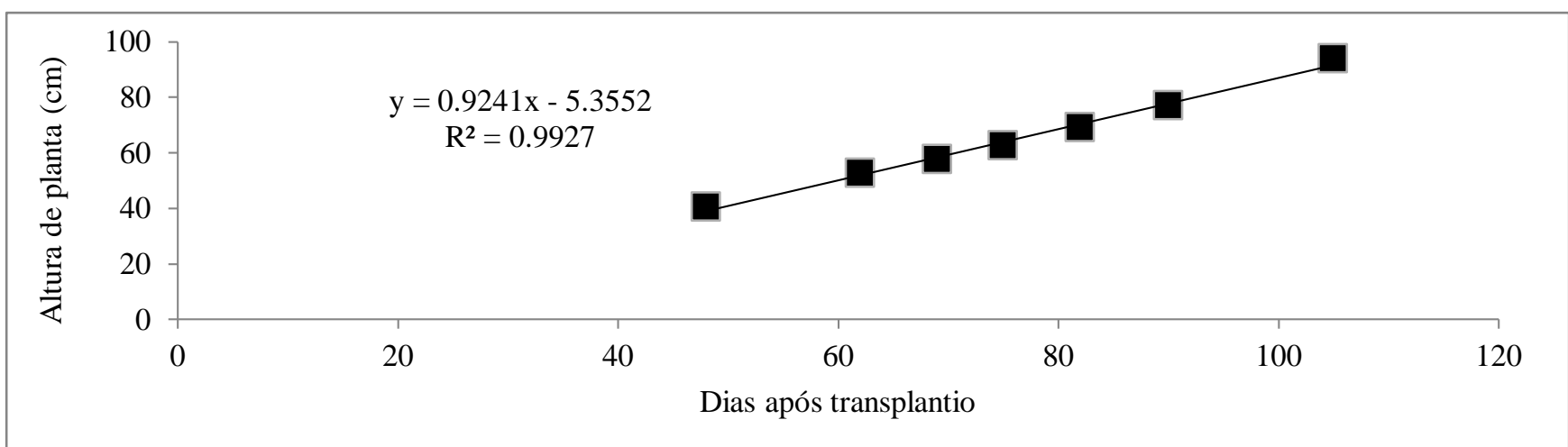

Figura 4. Altura de Planta dos 40 aos 110 DAT, heliconia Golden Torch, em ambiente semiprotegido JuazeiroBA.

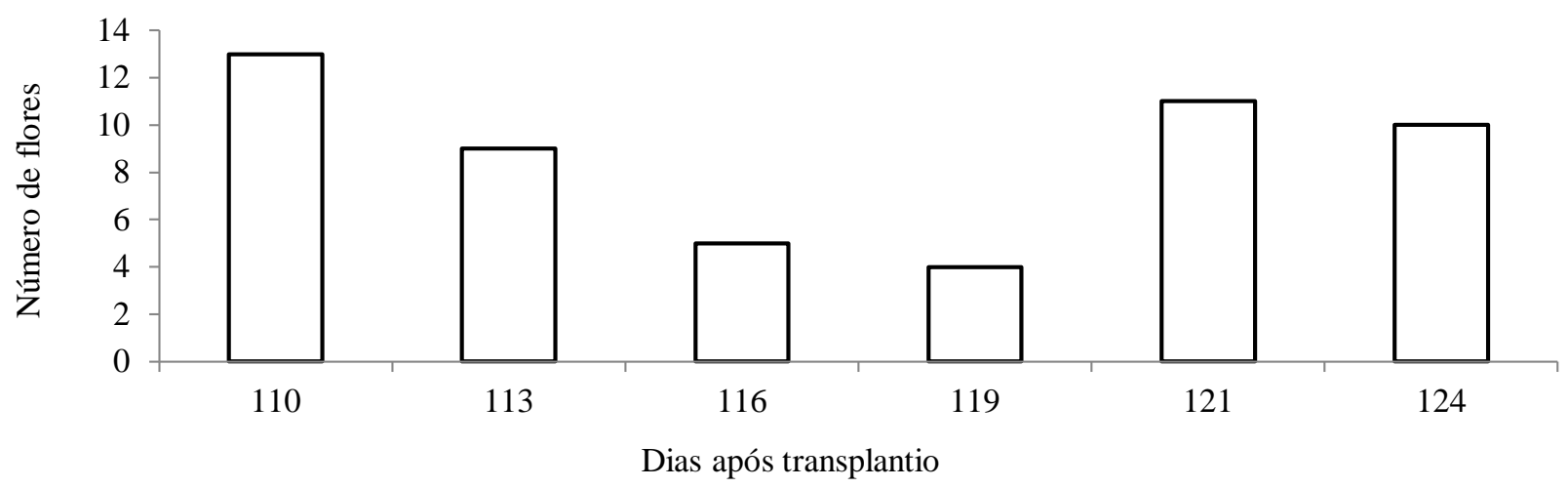

Figura 5. Numero de flores colhidas dos 110 aos 124 DAT, heliconia Golden Torch, em ambiente semiprotegido, Juazeiro-BA

O potencial matricial do solo na zona radicular de 0 - $40 \mathrm{~cm}$ manteve-se entre a capacidade de campo (-6 kPa), conforme Rivers e Shipp (1978), para solo arenoso e - $27 \mathrm{kPa}$, sendo que o valor mais negativo foi observado aos 115 DAT. As lâminas de irrigação aplicadas 
e as precipitações pluviométricas foram suficientes para atender a demanda hídrica da cultura durante o período do estudo, sem déficit hídrico. Entretanto, promoveu, em alguns dias, perdas de água por percolação profunda, sendo tal processo facilitado devido a textura do solo e a baixa capacidade de armazenamento.

Similares resultados foram encontrados por Gomes et al. (2008) em estudo realizado com Alpinia purpurata, em Paraipaba - CE, em que o potencial mátrico variou entre a capacidade de campo e -15 $\mathrm{kPa}$, sendo possível verificar a ocorreram devido a textura arenosa do solo, às elevadas lâminas de irrigação aplicadas e às precipitações ocorridas ao longo do ciclo fenológico da cultura.

Em relação ao armazenamento de água no perfil do solo, constatou-se uma variação de $-32 \mathrm{~mm}$ a $+30 \mathrm{~mm}$ (Figura 6). Isto evidencia que houve aporte de água no perfil em período de baixo conteúdo de água do solo, e em outros onde havia excesso de umidade. Observam-se perdas por drenagem profunda favorecida pela textura arenosa (Neossolo

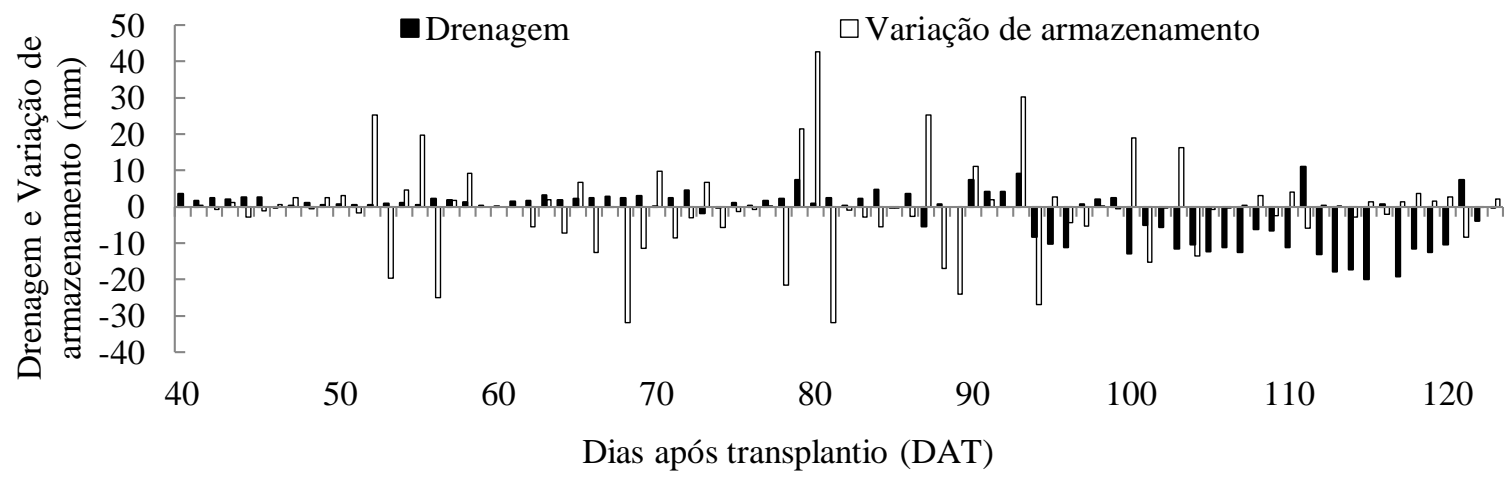

presença de fluxos de água negativos (perda por drenagem profunda), que segundo os autores,

Flúvico) e as precipitações ocorridas no período da pesquisa.

Figura 6. Drenagem e variação de armazenamento no solo, por balanço hídrico, ao longo do cultivo de helicônia Golden Torch, em ambiente semi-protegido, Juazeiro-BA.

Na Tabela 2 estão expostos os valores médios de Evapotranspiração da cultura (ETc), Evapotranspiração de referência (ETo) e o coeficiente da cultura (kc), para cada fase fenológica da helicônia Golden Torch, em ambiente telado, Juazeiro-BA.

Tabela 2. Evapotranspiração da cultura, evapotranspiração de referência e coeficiente de cultivo.
Dias após o plantio
Fase fenológicas
$\operatorname{ETc}\left(\mathrm{mm} \mathrm{d}^{-1}\right)$
ETo $\left(\mathrm{mm} \mathrm{d}^{-1}\right)$

(Kc)

$\begin{array}{ccccc}40-63 & \text { Inicial } & 4,0 & 6,28 & 0,63 \\ 64-81 & \text { Vegetativa } & 5,0 & 6,25 & 0,80\end{array}$

$82-122$

Floração-colheita

5,8

5,74

1,01

Houve aumento da ETc e do Kc, da fase inicial da cultura até a fase de floração- colheita, consequente do aumento do porte da cultura (incremento de área foliar, altura da planta) e das condições climáticas predominantes. A evapotranspiração da cultura acumulada 
durante a condução do experimento foi da ordem de 231,2 mm, correspondendo a um valor médio de $2,78 \mathrm{~mm} \mathrm{~d}^{-1}$.

Os valores médios e acumulados de ETc encontrados neste estudo foram superiores, aos reportados por Gondim et al. (2008) e Gomes et al. (2008).

Em estudo realizado por Gondim et al. (2008), com Heliconia bihai L. a evapotranspiração acumulada total foi de 174,7 mm, para todo o período, e os valores de evapotranspiração média de 2,2 $\mathrm{mm} \mathrm{dia}^{-1}$ durante a fase F2 (10\% até $80 \%$ de cobertura vegetal); 2,3 mm dia ${ }^{-1}$ na fase F3 (80\% de cobertura até o início da floração) e $2,5 \mathrm{~mm} \mathrm{dia}^{-1}$ na fase $\mathrm{F} 4$ (início da floração até a colheita), em estudo realizado em região litorânea do Ceará e cuja a precipitação acumulada no período foi de $967,4 \mathrm{~mm}$.

Em pesquisa com Heliconia psittacorum L $\mathrm{x} H$. spathocircinada (Arist), em ambiente telado coberto por malha preta, com 50\% de sombreamento, em Paraipaba - CE, obtiveram valores acumulado de ETc de 291,0 mm e valores médios de 2,00 $\mathrm{mm} \mathrm{dia}^{-1}$, para a fase vegetativa (40-172 dias após o plantio, DAP) e de 3,60 mm dia ${ }^{-1}$, para a fase de floração (173190 DAP) e um valor de 390,9 mm de precipitação efetiva (Gomes et al., 2008).

Poucas são as informações que relatam o coeficiente de cultivo para a helicônia. $\mathrm{O}$ valor médio de Kc observado neste estudo, durante a fase vegetativa, é semelhante ao reportado por Gondim et al. (2008) ao estudarem a Heliconia bihai L. na região litorânea do Estado do Ceará, (kc de 0,80 e 0,60 utilizando o método de balanço hídrico e Penman-Moteith FAO, respectivamente), estes autores verificaram que os coeficiente de cultivo (Kc) variaram em função do método de estimativa da ETo, sendo maiores quando utilizado o tanque Classe A instalado dentro do ambiente protegido.
Gomes et al. (2006), em condições semelhantes ao presente estudo, encontraram para a heliconia, variedade Alan carle, valores médios de coeficientes de cultivo de 0,78 e 1,26 para a fase vegetativa e floração. Contudo, os valores de coeficiente de cultivo não são semelhantes aos apresentados pela FAO, para bananeira, que têm sido recomendado para o manejo de irrigação da helicônia, devido no passado terem sido taxonomicamente pertencentes à mesma família de plantas (musaceae). Indicando a importância da determinação e utilização de coeficientes de cultivo para cada localidade e tipo de cultura.

\section{CONCLUSÕES}

A helicônia Golden Torch apresentou uma taxa de evapotranspiração média de $2,78 \mathrm{~mm} \mathrm{~d}^{-1}$, totalizando 231,2 $\mathrm{mm}$ no período estudado.

Os valores médios dos coeficientes de cultivos encontrados foram de 0,63 na fase inicial, 0,80 na fase vegetativa e de 1,01 na fase de florescimento-colheita.

\section{REFERÊNCIAS BIBLIOGRÁFICAS}

BASSOI, L. H., TEIXEIRA, A. H. de C;SILVA, J.A . M.; SIVA, E . E. G.; RAMOS, C. M. C.; TARGINO, E. de L.; MAIA, J .L. T.; FERREIRA, M. de N. L. Consumo de água e coeficiente de cultura em bananeira irrigada por microaspersão. Petrolina: Embrapa SemiÁrido, 2001. 4p. (Embrapa Semi Arido Comunicado Técnico, 108).

GOMES, A. R. M. et. al. Estimativa da evapotranspiração e coeficiente de cultivo da Heliconia psittacorum $L \quad x \quad$ H spathocinada (arist) cultivada em ambiente protegido. Revista Ciência Agronômica, v. 37, n. 01, p. 13-18, 2006. 
GOMES, A. R. M. et. al. Evapotranspiração e coeficiente de cultiv o da Alpinia purpurata. Revista Ciência Agronômica, v. 39, n.4, p. 481 - 486, 2008.

GONDIM, R. S.; GOMES, A. R. M., BEZERRA, F. C., COSTA, C. A. G. PEREIRA, N. S. Estimativa da evapotranspiração e coeficiente de cultivo da Heliconia bihai L., cultivada em ambiente protegido. Revista Brasileira de Horticultura Ornamental. v. 14, n.1, p. 53 - 58, 2008.

MOSCA, J. L. et al. Helicônia: descrição, colheita e pós-colheita. Fortaleza: Embrapa Agroindústria Tropical, 2005. 32p. 